\title{
Expression and pH-dependence of the Photosystem II Subunit S from Arabidopsis thaliana
}

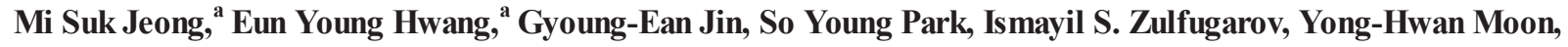 \\ Choon-Hwan Lee, and Se Bok Jang*
}

\author{
Department of Molecular Biology, College of Natural Sciences, Pusan National University, Busan 609-735, Korea \\ *E-mail: sbjang@pusan.ac.kr \\ Received March 15, 2010, Accepted March 30, 2010
}

\begin{abstract}
Photosynthesis uses light energy to drive the oxidation of water at an oxygen-evolving catalytic site within photosystem II (PSII). Chlorophyll binding by the photosystem II subunit S protein, PsbS, was found to be necessary for energy-dependent quenching (qE), the major energy-dependent component of non-photochemical quenching (NPQ) in Arabidopsis thaliana. It is proposed that PsbS acts as a trigger of the conformational change that leads to the establishment of nonphotochemical quenching. However, the exact structure and function of PsbS in PSII are still unknown. Here, we clone and express the recombinant PsbS gene from Arabidopsis thaliana in E. coli and purify the resulting homogeneous protein. We used various biochemical and biophysical techniques to elucidate PsbS structure and function, including circular dichroism (CD), fluorescence, and DSC. The protein shows optimal stability at $4{ }^{\circ} \mathrm{C}$ and $\mathrm{pH} 7.5$. The $\mathrm{CD}$ spectra of PsbS show that the conformational changes of the protein were strongly dependent on $\mathrm{pH}$ conditions. The $\mathrm{CD}$ curve for PsbS at $\mathrm{pH} 10.5$ curve had the deepest negative peak and the peak of PsbS at pH 4.5 was the least negative. The fluorescence emission spectrum of the purified PsbS protein was also measured, and the $\lambda_{\max }$ was found to be at $328 \mathrm{~nm}$. PsbS revealed some structural changes under varying temperature and oxygen gas condition.
\end{abstract}

Key Words: Photosystem II subunit S, Expression, $\mathrm{pH}$ dependence, Temperature dependence

\section{Introduction}

Light is essential for photosynthesis in plants, but the supply of light in natural environments is not sustained. At increasing light extremes, photosynthetic utilization of absorbed light energy reaches saturation, while light absorption continues to increase. This result was reported as a mismatch between excitation of photosynthetic pigments and a plant's ability to use the excitation energy for photosynthesis. ${ }^{1}$ Photosynthesis uses light energy to drive the oxidation of water at an oxygen-evolving catalytic site within photosystem II (PSII). Recent work has reported a $3.5 \AA$ resolution structure of PSII from the cyanobacterium Thermosynechococcus elongatus and proposed a structure of the oxygen-evolving center (OEC). ${ }^{2}$

The chlorophyll-binding protein Photosystem II subunit $\mathrm{S}$, PsbS, was found in Arabidopsis thaliana as a specific protein essential for the energy-dependent component of non-photochemical quenching (NPQ). NPQ protects plants under photooxidative and photoinhibitive stress by dissipating immoderate light energy, for example, as heat. ${ }^{3}$ In Arabidopsis thaliana, the major component of NPQ is known as $\mathrm{qE}$, which is dependent upon an increase in the $\mathrm{pH}$ difference across the thylakoid membrane. ${ }^{4,5}$ In higher plants, the PsbS protein plays a central role in NPQ; its removal by mutation strongly reduces $\mathrm{qE}$ induction and causes rapid $\mathrm{qE}$ relaxation.

Because $\mathrm{qE}$ involves the de-excitation of singlet-excited chlorophyll, it is also sometimes referred to as feedback de-excitation. ${ }^{6}$ The feedback mechanism is rapid and is thought to represent a protective mechanism that prevents PSII photoinhibition

${ }^{\mathrm{a}}$ These authors contributed equally to this article. during short-term fluctuations in light intensity. ${ }^{7,8}$ The rapid feedback mechanism depends on the photosystem II subunit $\mathrm{S}$ (PsbS) protein, which belongs to the superfamily of light-harvesting protein complexes (LHC). ${ }^{9}$ PsbS was discovered in isolated PSII systems, but its structure and function within PSII are still unknown. ${ }^{10}$

Here we clone and express the recombinant PsbS gene from Arabidopsis thaliana in E. coli to generate a homogeneous protein. In order to elucidate its structure and function, we used various biochemical and biophysical techniques, including circular dichroism (CD), fluorescence, and differential scanning calorimetry (DSC). In addition, we describe the stability and $\mathrm{pH}$-dependent structure of the protein. This information on the PsbS protein in photosystem II will aid further studies on the mechanism of the oxygen-evolving reaction.

\section{Materials and Methods}

Cloning and expression. A full-length PsbS gene from Arabidopsis thaliana was cloned into the C-terminal His-tagged fusion protein vector $\mathrm{pET}-28 \mathrm{a}$. The recombinant PsbS protein fusion was transformed into the expression host Escherichia coli BL21(DE3) (Stratagene). A single colony was inoculated into $5 \mathrm{~mL}$ of LB (Luria Bertani) medium containing $50 \mu \mathrm{g} / \mathrm{mL}$ ampicillin and grown overnight at $37{ }^{\circ} \mathrm{C}$. Bacteria were cultivated using a flask containing $1 \mathrm{~L}$ of LB medium at $37{ }^{\circ} \mathrm{C}$ until the $\mathrm{OD}_{600}$ reached 0.5 - 0.7. Isopropyl $\beta$-D-thiogalactopyranoside (IPTG) was added at a final concentration of $1 \mathrm{mM}$ to induce recombinant PsbS protein expression (264 amino acids). After 8 - $12 \mathrm{~h}$ induction at $16^{\circ} \mathrm{C}$, the cells were harvested by centri- 
fugation at $4,500 \mathrm{rpm}$ for $25 \mathrm{~min}$ at $4{ }^{\circ} \mathrm{C}$, and the supernatant was discarded. Cell pellets were either immediately used or stored frozen at $-70{ }^{\circ} \mathrm{C}$ until needed. The cells were resuspended in buffer A (50 mM Tris- $\mathrm{HCl}[\mathrm{pH} 7.5]$ and $150 \mathrm{mM} \mathrm{NaCl})$ and disrupted by sonication on ice. After sonication, remaining whole cells and debris were removed by centrifugation at 13,500 rpm for $45 \mathrm{~min}$.

Purification of PsbS protein. The clear supernatant was loaded onto a Ni-NTA (Amersham-Pharmacia Biotech) column and pre-equilibrated with buffer A. The column was washed with buffer A containing $20 \mathrm{mM}$ imidazole at a flow rate of $2.5 \mathrm{~mL} /$ min, and elution of the bound protein was achieved using varying concentrations of imidazole from 50 to $200 \mathrm{mM}$. Protein elution was monitored at $280 \mathrm{~nm}$ and the resulting fractions were analyzed by electrophoresis on $12 \%$ SDS-PAGE gels. The eluted protein solution from the previous step was applied to a column of Q Sepharose fast flow resin (Amersham-Pharmacia Biotech) for ion exchange chromatography and washed extensively with buffer A. Elution was performed using a gradient of $\mathrm{NaCl}$ solutions in $50 \mathrm{mM}$ Tris-HCl buffer. Then gel filtration was performed on an HPLC using a Superdex 75 column (Amersham-Pharmacia Biotech) equilibrated in buffer A. Fractions containing purified PsbS protein were collected and concentrated to a final volume of $1 \mathrm{~mL}$ by centrifuging at 2,000 rpm using ultrafiltration devices. All the purification steps were analyzed and visualized by SDS-PAGE using $12 \%$ polyacrylamide gels and Coomassie brilliant blue staining.

Protein concentration analysis. Concentrations of the PsbS protein were measured using the Bradford method with a BioRad protein assay kit using Bovine Gamma Globulin (BGG) as a standard. Measurements were determined by BioPhotometer using an UVette of $10 \mathrm{~mm}$ optical path length.

MALDI-TOF mass analysis. For in-gel digestion, $10 \mu \mathrm{L}$ of trypsin solution $(2 \mathrm{ng} / \mathrm{L}$ in $25 \mathrm{mM}$ ammonium bicarbonate [pH 8.0] was added for digestion overnight at $37^{\circ} \mathrm{C}$. Peptides were extracted with $50 \%$ CAN/1\% TFA (trifluoroacetic acid) and dried in a vacuum desiccator overnight, followed by reconstitution with $3 \mu \mathrm{L}$ of CHCA ( $\alpha$-Cyano-4-hydroxy-cinnamic acid) matrix solution ( $8 \mathrm{mg}$ of CHCA in $1 \mathrm{~mL}$ of $50 \% \mathrm{CAN} / 1 \% \mathrm{TFA}$ ). One microliter of sample was loaded onto a $96 \times 2$ MALDI plate. The peptide mass was acquired with the Voyager DE-PRO MALDI-TOF mass spectrometer (Applied Biosystems, Framingham, MA) in reflector mode under $20,000 \mathrm{~V}$ of accelerating voltage, $76 \%$ grid voltage and $0.002 \%$ guide- wire voltage. Cal Mix 2 from the MALDI-TOF MS calibration kit (Applied Biosystems, Framingham, MA) was used for external calibration, and autolysis fragments of trypsin were used for internal calibration. Peptide matching and protein identification were carried out with the Mascot peptide mass fingerprint.

Circular dichroism (CD) measurement. Circluar dichroism measurements were carried out with a spectropolarimeter (JASCO J-715) using a $0.1 \mathrm{~cm}$ cell at $0.2 \mathrm{~nm}$ intervals at $25^{\circ} \mathrm{C}$. The CD spectra of the purified recombinant PsbS protein (the average of five scans) were recorded in the 190 - $260 \mathrm{~nm}$ range. Far-UV CD spectra were taken at the protein concentration of $0.2 \mathrm{mg} / \mathrm{mL}$. The CD spectra were obtained in milli-degrees and converted to molar ellipticity prior to secondary structure analysis. Calculation of the content of the protein's secondary structure elements was performed using the CDNN program. ${ }^{11}$ The CD spectra of the PsbS protein were obtained at various $\mathrm{pH}$ levels, adjusted with buffers.

Time comelated single photon counting (TCSPC) spectrometry. Steady-state fluorescence emission spectra were acquired by using a Time Correlated Single Photon Counting Spectrometer (FLS920 TCSPC, Edinburgh, UK). Counts were recorded for wavelengths ranging from 300 to $400 \mathrm{~nm}$ with excitation at $295 \mathrm{~nm}$. All spectra were recorded at room temperature $\left(25^{\circ} \mathrm{C}\right)$ with buffer $\mathrm{A}$ and protein. Each curve was taken at a protein concentration of $0.3 \mathrm{mg} / \mathrm{mL}$. The fluorescence spectra of the PsbS protein were measured at various $\mathrm{pH}$ levels, adjusted with buffers.

Fluorescence spectroscopy. Fluorescence spectra were collected using a HITACHI F-4500 spectrometer. The emission spectra were recorded at a PsbS protein concentration of $0.5 \mathrm{mg} /$ $\mathrm{mL}$ using an excitation wavelength of $285 \mathrm{~nm}$ in a $1 \mathrm{~cm}$ path length cuvette. The widths of the excitation and emission slits were $5 \mathrm{~nm}$. The spectra of the PsbS protein were obtained at various $\mathrm{pH}$ levels, adjusted with buffers.

Differential scanning calorimetry (DSC). Differential scanning calorimetric (DSC) measurements were carried out on a DSC 204 F1 Phoenix calorimeter (NETZSCH DSC, USA). 8 mg of protein was placed in an aluminum pan and immediately sealed. It was heated from $0{ }^{\circ} \mathrm{C}$ to $90{ }^{\circ} \mathrm{C}$ with a heat flow of $1{ }^{\circ} \mathrm{C} /$ min. An empty pan was used as a reference. The sensitivity was $0.1 \mu \mathrm{w}$, and the sensor time constant was 0.6. During DSC protein analysis, the reference was in the same state (liquid), and it was placed in a reference crucible also made of aluminum. The onset temperature (Tm), peak transition or denaturation temperature $(\mathrm{Td})$, enthalpy of denaturation $(\Delta \mathrm{H})$ and cooperativity, represented by the width at half-peak height $(\Delta \mathrm{T} 1 / 2)$, were computed from the thermograms by Universal Analysis Version 3.0.3. All samples were examined at least 2 times by repeating the heating-cooling cycles. In all cases, the sealed pans containing protein samples and references were equilibrated.

Protein stability assay. Assays of protein stability were carried out in a reaction mixture $(100 \mu \mathrm{L})$ consisting of $50 \mathrm{mM}$ Tris$\mathrm{HCl}$ buffer, $150 \mathrm{mM} \mathrm{NaCl}$, and $20 \mu \mathrm{L}$ of protein using an Eppendorf BioPhotometer. The protein stability was assayed under the wavelength of $280 \mathrm{~nm}$. Reactions were performed at various temperature and $\mathrm{pH}$ for $5 \mathrm{~min}$.

\section{Results and Discussion}

Full-length PsbS from Arabidopsis thaliana was verified by DNA sequencing. The pET-28a vector was used in the expression of a His-fusion PsbS protein construct. The construct was transformed into the expression host E. coli BL21(DE3), and protein expression was induced by $1 \mathrm{mM}$ IPTG. Overexpressed PsbS protein was observed mainly in the supernatant of the large-scale culture (Fig. 1). The expressed protein was identified at the molecular weight of $24 \mathrm{kDa}$, as expected for His-tagged PsbS. The PsbS protein was purified using a Ni-NTA column, which has affinity for the His-tag fusion partner. The column was washed with $50 \mathrm{mM}$ Tris- $\mathrm{HCl}[\mathrm{pH}$ 7.5] buffer containing $200 \mathrm{mM} \mathrm{NaCl}$. The protein fractions were eluted using from 50 to $200 \mathrm{mM}$ immidazole in $50 \mathrm{mM}$ Tris- $\mathrm{HCl}$ [pH 7.5] buffer 
Table 1. Yield volumes and concentrations of PsbS proteins at each preparatory step

\begin{tabular}{lc}
\hline Ni-column & 60 \\
Volume $(\mathrm{mL})$ & 0.6 \\
Concentration $(\mathrm{mg} / \mathrm{mL})$ & 85 \\
Purity $(\%)$ & \\
& \\
Q-Sepharose & 60 \\
Volume (mL) & 0.5 \\
Concentration $(\mathrm{mg} / \mathrm{mL})$ & 90 \\
Purity $(\%)$ & \\
& \\
Superdex 75 & 65 \\
Volume (mL) & 0.4 \\
Concentration $(\mathrm{mg} / \mathrm{mL})$ & 95 \\
Purity $(\%)$ & \\
\hline
\end{tabular}

(A)
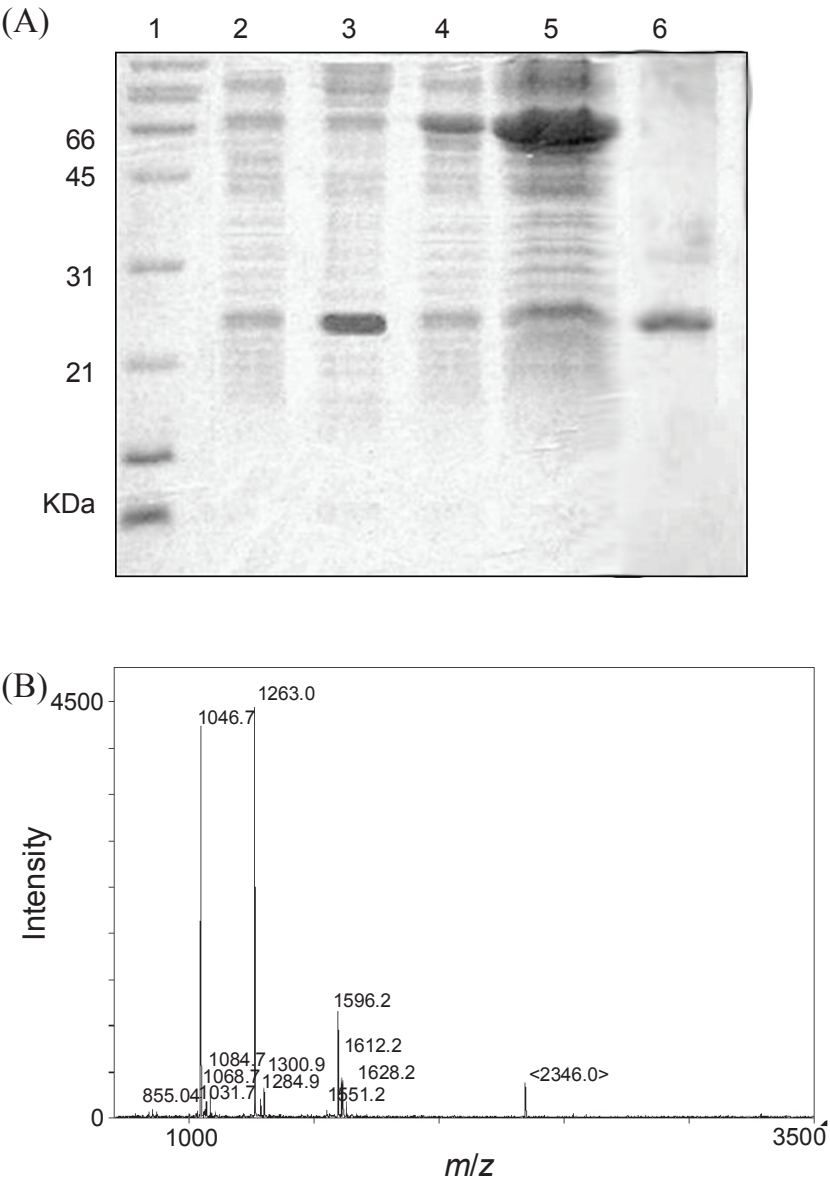

Figure 1. SDS-PAGE of the soluble PsbS protein and the MALDITOF mass spectrum. (A) His-tagged PsbS expressed in E. coli BL21 (DE3). Lane 1, molecular weight marker; lane 2, supernatant of lysed bacteria before induction by IPTG; lane 3, supernatant after induction by IPTG; lane 4, pellet of before induction by IPTG; lane 5, pellet of lysed bacteria after induction by IPTG; lane $6,3 \mu \mathrm{L}$ of the purified protein. (B) MALDI-TOF peptide spectrum of PsbS. Peptide matching and protein searches based on the peptide mass fingerprint were performed using Mascot.

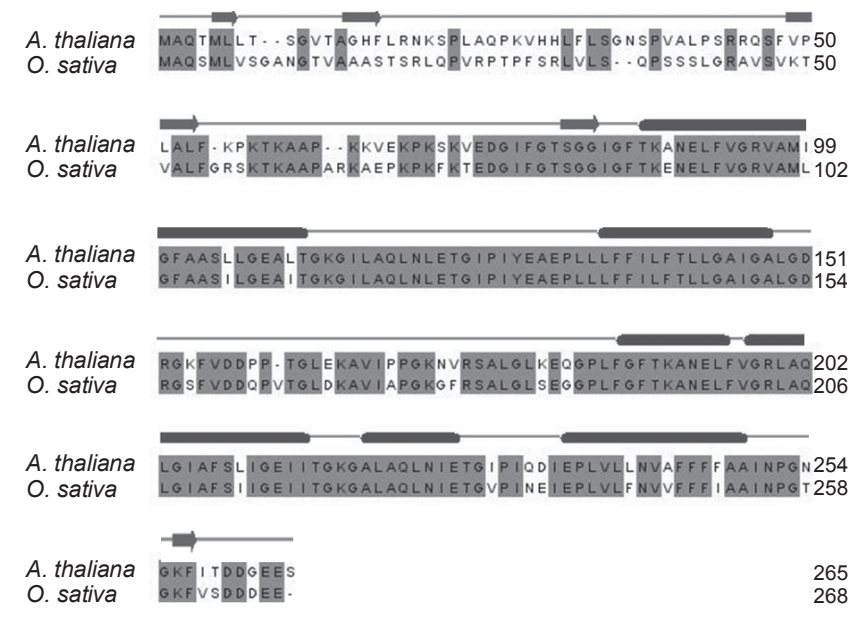

Figure 2. Alignments and secondary structure of the amino acid sequences of PsbS from Arabidopsis thaliana and Oryza sativa [GenBank Accession No. AAD28778 for AtPsbS and BAB89811 for OsPsbS]. The sequences were aligned using Jalview. Residues that are identically conserved in the two species are colored in gray. The secondary structure of the PsbS protein was predicted. Alpha-helices are shown as ellipses, and $\beta$-sheets are shown as arrows. Loops are shown by gray lines.

containing $200 \mathrm{mM} \mathrm{NaCl}$. Subsequently, fractions including the PsbS protein were loaded onto a Q-Sepharose fast flow anion-exchange column and eluted with a gradient of $\mathrm{NaCl}$ solution. The PsbS protein eluted from this column in the unbound fractions, and was further purified using gel filtration chromatography. Yields of the protein during multi-step purification under non-denaturing conditions are shown in Table 1. The soluble PsbS protein was successfully purified to homogeneity and concentrated to $26 \mathrm{mg} / \mathrm{mL}$ (Fig. 1).

MALDI-TOF MS studies revealed the approximate molecular mass of the recombinant PsbS protein, which was in accordance with its theoretical mass prediction. The monoisotopic masses obtained for the individual peptides were unrestricted. Mass fingerprinting analysis of the protein was performed according to the peptide mass tolerance of $50 \mathrm{ppm}$. The maximum appeared at $m / z 1263$ (Fig. 1C). Sequences of the digested peptides were matched with protein sequences in the database using the MASCOT program (http: //www.matrixscience.com). The protein was confirmed to be PsbS (Accession No. AF134 131.1 and $\mathrm{pI}$ value 9.25).

We compared the amino acid sequences of PsbS from Arabidopsis thaliana (AtPsbS) with its homolog in Oryza sativa (OsPsbS) by using the Jalview program. AtPsbS and OsPsbS showed 74\% identity in their amino acid sequences and the conserved residues are colored blue (Fig. 2). The secondary structure of the PsbS protein was predicted by using the JNET program. Alpha-helices are shown as ellipses and $\beta$-sheets are shown as arrows. Loops were shown by lines in gray (Fig. 2).

The effects of temperature and $\mathrm{pH}$ on protein stability were analyzed by photometry. To examine these effects, PsbS was stored at varying temperatures $\left(0-55^{\circ} \mathrm{C}\right)$ and $\mathrm{pH}(4.5-10.5)$ for $5 \mathrm{~min}$. The protein showed optimal stability at $4{ }^{\circ} \mathrm{C}$ and $\mathrm{pH} 7.5$ and the stability began decreasing at $25-55^{\circ} \mathrm{C}$ (Fig. 3A and 3B). 
To observe PsbS folding properties, the protein was observed under varying $\mathrm{pH}$ conditions by $\mathrm{CD}$ spectroscopy (Fig. 4A). These results show that the $\mathrm{CD}$ curve for PsbS at $\mathrm{pH} 10.5$ curve had the deepest negative peak and the peak of PsbS at $\mathrm{pH} 4.5$ was the least negative. The PsbS at pH 10.5 is composed mostly of alpha-helical structure. Protein structures are in general strongly dependent on solution condition such as $\mathrm{pH}$. The $\mathrm{pH}$ changes induce protonation-deprotonation of dissociable groups of proteins, the carboxylic acid (aspartic acid and glutamic acid) and amine (lysine, arginine and histidine) side groups. Due to the charge density changes the electrokinetic properties of the proteins also vary with $\mathrm{pH}$. Therefore, it would lead an unfolded state corresponding to an extremely low $\mathrm{pH}$ to assume all the ionizable side chains in the PsbS to be fully protonated or deprotonated. It can be composed lowly of alpha-helical structure as the polarity was decreased. The CD spectra of PsbS show that each $\mathrm{pH}$ affected the conformational changes of PsbS to a different extent (Fig. 4A). Recently, it has been demonstrated that the dimer/monomer ratio of PsbS in thylakoid membranes depends on $\mathrm{pH}$, with acidic luminal $\mathrm{pH}$ favoring the monomer. ${ }^{12}$ The $\mathrm{CD}$ spectrum of $\mathrm{PsbS}$ at $\mathrm{pH} 7.5$ exhibited two negative maximums at approximately $208 \mathrm{~nm}$ and $222 \mathrm{~nm}$, which is a typical pattern for an $\alpha$-helix protein. These results are consistent the secondary structure of the protein predicted in Fig. 2. Exposing the protein to $\mathrm{pH} 4.5$ significantly changed the conformations of the $\alpha$-helices, $\beta$-sheets, and random coils.

(A)

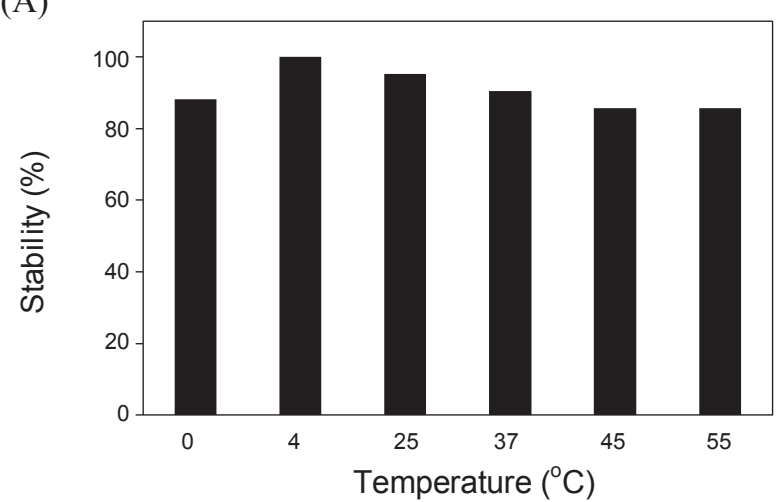

(B)

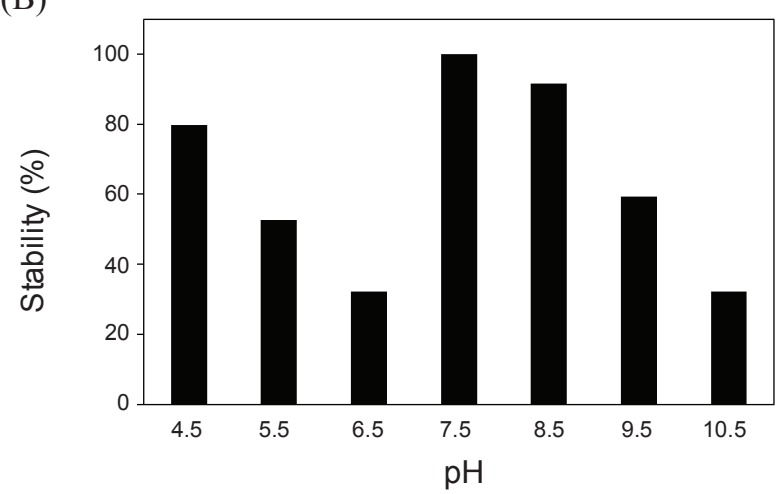

Figure 3. (A) and (B) Effects of temperature and pH on the stability of the PsbS protein. Protein stability was assayed by Biophotometer at $280 \mathrm{~nm}$. Reactions were carried out for $5 \mathrm{~min}$ at various temperatures and $\mathrm{pH}$. The optimum temperature and $\mathrm{pH}$ were at $4{ }^{\circ} \mathrm{C}$ and $\mathrm{pH}$ 7.5.
The CD spectrum at $\mathrm{pH} 7.5$, except for the negative peak depth, resembled that of the $\mathrm{pH} 8.5$ spectrum. These $\mathrm{pH}$-dependent changes in the secondary structures of the protein can be due to either local structural perturbation or an increase in the fraction of unfolded protein in solution.

To better observe the folding properties of PsbS, the protein structure was measured by CD spectroscopy under excess oxygen gas (data not shown). This observation provides the basis for understanding the conformational properties and oxygen sensitivity of PsbS in an aerobic atmosphere. There is a gap between the dual peaks at $215 \mathrm{~nm}$, characteristic for $\alpha$-helices. The positive peak was much attenuated, and the magnitude of the negative peak was less than for the folded conformation. This indicates that the conformational changes of the PsbS protein under oxygen gas occurred in both the $\alpha$-helix and $\beta$-sheet structures. Thus, exposure to oxygen gas caused progressive conformational changes of the protein within the $\alpha$-helical and $\beta$-sheets, and the characteristic bands of random or disordered structures appeared.

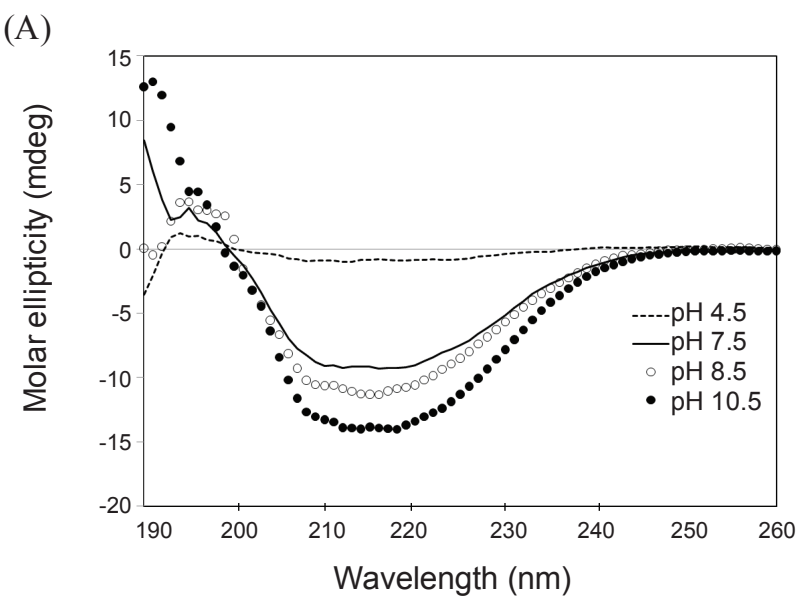

(B)

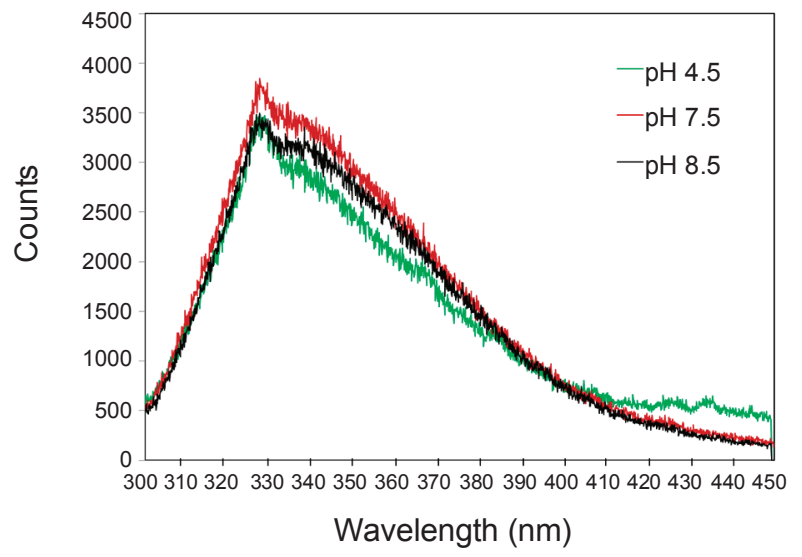

Figure 4. Far-UV Circular dichroism (CD) and fluorescence emission spectra of PsbS and its variants. (A) The CD spectrum of PsbS was measured from 190 to $260 \mathrm{~nm}$, and the CD signal was merged into CDNN. Purified proteins were measured in buffer containing $50 \mathrm{mM}$ Tris- $\mathrm{HCl}$ and $200 \mathrm{mM} \mathrm{NaCl}$. These spectra were the result of 3 scans. (B) Effect of $\mathrm{pH}$ on the fluorescence emission spectra of PsbS. Emission changes in the fluorescence of $\mathrm{PsbS}$ at $\mathrm{pH} 4.5,7.5$, and 8.5 are shown. Fluorescence intensity was scanned from 300 to $400 \mathrm{~nm}$ with excitation at $285 \mathrm{~nm}$. 
(A)

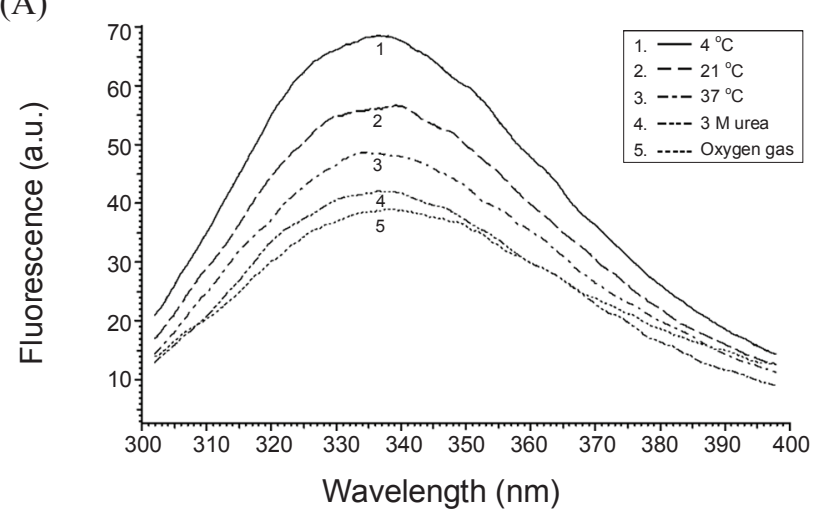

(B)

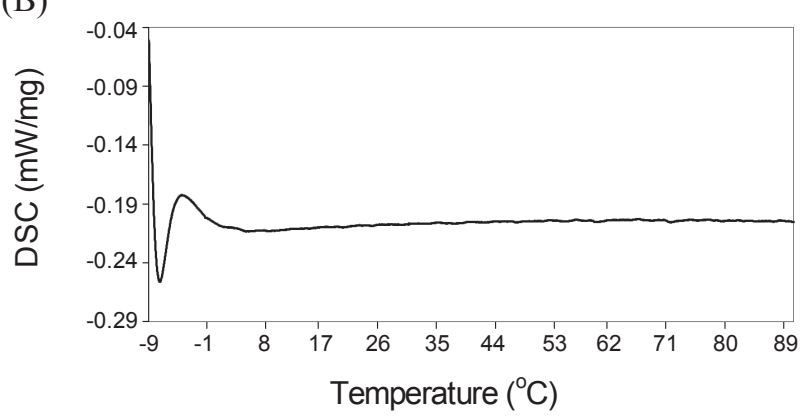

Figure 5. Effects of temperature and denaturation on fluorescence emission spectra of PsbS and DSC analyses. (A) Emission changes in fluorescence of PsbS at 4, 25, and $37^{\circ} \mathrm{C}$, in the presence of oxygen gas or denatured in $3 \mathrm{M}$ urea are shown in curves 1-5, respectively. Fluorescence emission intensity was scanned from 300 to $450 \mathrm{~nm}$ with excitation at $285 \mathrm{~nm}$. (B) DSC analysis of PsbS protein. Temperatures were set from $-10{ }^{\circ} \mathrm{C}$ to $90{ }^{\circ} \mathrm{C}$. The heat flow was $1{ }^{\circ} \mathrm{C} / \mathrm{min}$. The concentration of the PsbS protein was $1 \mathrm{mg} / \mathrm{mL}$. The melting temperature (Tm) and width are $-0.9{ }^{\circ} \mathrm{C}$ and $0.2{ }^{\circ} \mathrm{C}$, respectively.

Steady-state fluorescence analysis used the TCSPC system. The maxima of the fluorescence emission spectra were 328 and $330 \mathrm{~nm}$ at $\mathrm{pH} 4.5, \mathrm{pH} 8.5$, and $\mathrm{pH} 7.5$ (Fig. 4B). The $\lambda_{\max }$ at $\mathrm{pH} 4.5$ was almost identical to that at $\mathrm{pH} 8.5$. However, the spectrum at $\mathrm{pH} 7.5$ showed the strongest intensity, with about 350 higher fluorescence counts at the $\lambda_{\max }$ than the spectra at $\mathrm{pH} 4.5$ and $\mathrm{pH}$ 8.5. This result suggests that PsbS at $\mathrm{pH} 4.5$ and $\mathrm{pH} 8.5$ have some disordered secondary structure and that there are some $\mathrm{pH}$-dependent conformational changes. The model of the PsbS protein was postulated that the decrease in $\mathrm{pH}$ $(<5.0)$ in the lumen may protonate the carboxylate group of Glu and make it charge neutral. The salt-bridge may break, inducing a change in the conformation of PsbS. ${ }^{15}$ A rigid and hydrophobic environment for the PsbS protein can cause a decrease in fluorescent intensity. The fluorescence spectra of the protein exhibited an appreciable change as a function of $\mathrm{pH}$, as shown in Fig. 4B. The protein exhibited optimal stability at $\mathrm{pH} 7.5$.

Fluorescence spectra of PsbS were also recorded at 4, 25, $37^{\circ} \mathrm{C}$, and in the presence of oxygen gas and urea, respectively. PsbS protein was pre-equilibrated in buffer A with urea for equilibrium and kinetic measurements of unfolding. The excitation wavelength was $285 \mathrm{~nm}$ and emission was measured at
$335 \mathrm{~nm}$. Compared to that at $4{ }^{\circ} \mathrm{C}$, PsbS fluorescence intensity decreased at $25^{\circ} \mathrm{C}$ or $37^{\circ} \mathrm{C}$, suggesting that the proteins at $25^{\circ} \mathrm{C}$ or $37^{\circ} \mathrm{C}$ have some disordered secondary structures (Fig. 5A). $\mathrm{PsbS}$ appears to undergo some degree of temperature dependent conformational change. Fluorescence emission spectra for the purified folded and urea-unfolded PsbS proteins were recorded over 300 - $400 \mathrm{~nm}$ (Fig. 5A). The maximum fluorescence emission of unfolded PsbS in the presence of urea was approximately $50 \%$ lower in intensity compared to the folded state at $4{ }^{\circ} \mathrm{C}$. The observation provides an explanation to why the protein requires a prolonged incubation at low temperature for the full activity. The fluorescence intensities (counts) were about 68 a.u. at $4{ }^{\circ} \mathrm{C}, 41$ a.u. in $3 \mathrm{M}$ urea, and 38 a.u. with oxygen gas. PsbS protein folding is optimized at $4{ }^{\circ} \mathrm{C}$, and we conjecture that protein stability dropped in the oxygen-gas environment. Under oxidative environment, formation of disulfide bridges occurs within the lumen and it may be leading to conformational changes of the PsbS protein.

Differential scanning calorimetry (DSC) was used to analyze the effects of heat on protein stability (Fig. 5B). ${ }^{16-17}$ DSC scans were performed for conditions under which the protein was irreversibly unfolded. The temperature for minimal heat absorption by the protein was $-0.9^{\circ} \mathrm{C}$. In our study, the protein showed no thermal transitions or denaturation from $0{ }^{\circ} \mathrm{C}$ up to $90^{\circ} \mathrm{C}$.

In the present study, we measured the stability and conformational changes of recombinantly purified PsbS protein using various biochemical and biophysical techniques, including $\mathrm{CD}$, DSC, and fluorescence measurements. These results may provide insight into future biological characterization and conformational information of the PsbS protein. These results also demonstrate that PsbS can undergo temperature and $\mathrm{pH}$-dependent conformational changes. Future work will be aimed towards further structural and functional studies of the PsbS protein.

Acknowledgments. This study was supported by Basic Science Research Program through the National Research Foundation of Korea (NRF) funded by the Ministry of Education, Science and Technology (2009-0075586) to S.B.J and by Pusan National University in program Post-Doc. 2010 to M.S.J.

\section{References}

1. Graßes, T.; Pesaresi, P.; Schiavon, F.; Varotto, C.; Salamini, F.; Jahns, P.; Leister, D. Plant Physiology and Biochemistry 2002, 40, 41-49.

2. Ferreira, K. N.; Iverson, T. M.; Maghlaoui, K.; Barber, J.; Iwata, S. Science 2004, 303, 1831-1838.

3. Niyogi, K. K.; Li, X-P.; Rosenberg, V.; Jung, H. S. Journal of Experimental Botany 2005, 56, 375-382 .

4. Horton, P.; Ruban, A. V.; Walters, R. G. Annu. Rev. Pl. Physiol. Pl. Mol. Biol. 1996, 47, 655-684.

5. Niyogi, K. K. Annu. Rev. Pl. Physiol. Pl. Mol. Biol. 1999, 50, 333-359.

6. Li, X-P.; Phippard, A.; Pasari, J.; Niyogi, K. K. Functional Plant Biology 2002, 29, 1131-1139.

7. Bergantino, E.; Segalla, A.; Brunetta, A.; Teardo, E.; Rigoni, F.; Giacometti, G. M.; Szabo' I. Proceedings of the National Academy of Sciences USA 2003, 100, 15265-15270.

8. Li, X-P.; Müller Moule, P.; Gilmore, A. M.; Niyogi, K. K. Proceedings of the National Academy of Sciences USA 2002, 99, 15222-15227. 
9. Li, X-P.; Björkman, O.; Shih, C.; Grossman, A. R.; Rosenquist, M.; Jansson, S.; Niyogi, K. K. Nature 2000, 403, 391-395.

10. Horton, P.; Ruban, A. V.; Wentworth, M. Philosophical Transactions of the Royal Society London B 2000, 355, 1361-1370.

11. Gerald, B. (1997), CD spectroscopy Deconvolution, version 2.1.

12. Bergatino, E.; Segalla, A.; Brunetta, A.; Teardo, E.; Rigoni, F.; Giacometti, G. M.; Szabo, I. Proceedings of the National Academy of Sciences USA 2003, 100, 15265-15270.

13. Ghaemmaghami, S.; Oas, T. G. Nature Structural Biology 2001, $8,879-882$
14. Gorziglia, M.; Larrea, C.; Liprandi, F.; Esparza, J. The Journal of General Virology 1985, 66, 1889-1900.

15. Haripal, P. K.; Raval, H. K.; Raval, M. R.; Rawal, R. M.; Biswal, B.; Biswal, U. C. Journal of Molecular Modeling 2006, 12, 847853.

16. Hong, J.; Jeong, M. S.; Kim, J. H.; Kim, B. G.; Holbrook, S. R.; Jang, S. B. Bulletin of the Korean Chemical Society 2008, 29 , 381-388.

17. Ha, J. H.; Jeong, M. S.; Jo, W.; Jeong, M.; Jang, S. B. Bulletin of the Korean Chemical Society 2010, 2, 275-280. 